\title{
Psychometric properties of the Attitudes towards Medical Communication Scale in nursing students
}

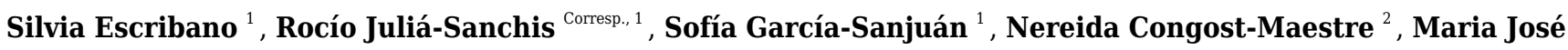 \\ Cabañero-Martínez ${ }^{1}$ \\ ${ }^{1}$ Faculty of Health Science, Department of Nursing, University of Alicante, San Vicente del Raspeig, Alicante, Spain \\ 2 Department of English Studies, Faculty of Arts, University of Alicante, San Vicente del Raspeig, Alicante, España \\ Corresponding Author: Rocío Juliá-Sanchis \\ Email address: rjulia@ua.es
}

Background: Adequate communication skills in healthcare professionals are one of the key elements required for achieving high-quality healthcare. Thus, measurement instruments able to assess the dimensions related to these skills, including attitudes towards communication, are useful and convenient tools.

Objectives: to (a) cross-culturally adapt and validate a scale to measure attitudes towards communication in a sample of nursing students in the Spanish environment; (b) describe the perceived attitudes of nursing degree students towards communication.

Methods: We conducted an instrumental study. First, we adapted the scale by applying a standardised linguistic validation procedure. After that, we determined its structural equivalence and evaluated its psychometric properties.

Participants: A total of 255 students participated; their average age was 22.66 years (SD $=4.75$ ) and $82 \%$ were female. Results: The internal consistency of the scale was adequate (0.78), and the data fit well with the model $(\mathrm{CFI}=0.99 ; \mathrm{TLI}=0.99$; RMSEA $=.01[95 \% \mathrm{Cl}=.00, .05])$. The overall instrument score poorly correlated with the self-efficacy in communication skills variable.

Conclusions: The attitudes towards communication scores for these nursing students were high. The Spanish version of the Attitudes Towards Health Communication scale had adequate psychometric properties and this tool could quickly and easily be applied to assess the attitudes of health profession students. 
1 Psychometric properties of the Attitudes towards 2 Medical Communication Scale in nursing students

3

4

5

7

7

8

9

10

11

12

13

14

15

16

17

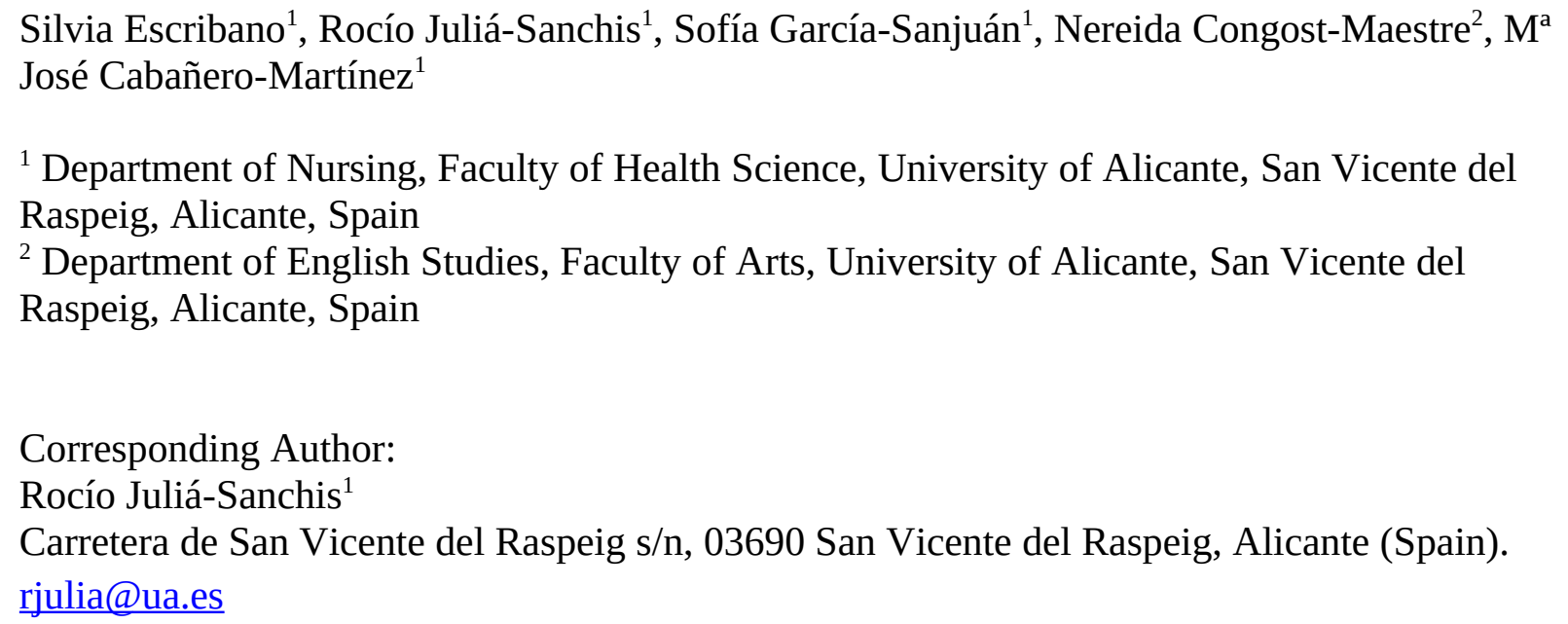




\section{Abstract}

Background: Adequate communication skills in healthcare professionals are one of the key elements required for achieving high-quality healthcare. Thus, measurement instruments able to assess the dimensions related to these skills, including attitudes towards communication, are useful and convenient tools.

Objectives: to (a) cross-culturally adapt and validate a scale to measure attitudes towards communication in a sample of nursing students in the Spanish environment; (b) describe the perceived attitudes of nursing degree students towards communication.

Methods: We conducted an instrumental study. First, we adapted the scale by applying a standardised linguistic validation procedure. After that, we determined its structural equivalence and evaluated its psychometric properties.

Participants: A total of 255 students participated; their average age was 22.66 years $(S D=4.75)$ and $82 \%$ were female.

Results: The internal consistency of the scale was adequate (0.78), and the data fit well with the model $(\mathrm{CFI}=0.99$; TLI $=0.99$; RMSEA $=.01[95 \% \mathrm{CI}=.00, .05])$. The overall instrument score poorly correlated with the self-efficacy in communication skills variable.

Conclusions: The attitudes towards communication scores for these nursing students were high. The Spanish version of the Attitudes Towards Health Communication scale had adequate psychometric properties and this tool could quickly and easily be applied to assess the attitudes of health profession students.

Keywords: attitudes; evidence-based practice, health communication; nursing students; psychometrics.

\section{Introduction}

Changes in health systems have resulted in an increased focus on providing quality, patientcentred care, which must consider the transmission of information, participation in decisionmaking, and the respectful and responsible treatment of patients (Mata et al., 2019). This process prioritises the needs of patients and tries to improve the quality of their health and well-being as well as their satisfaction and the quality of their healthcare.

The literature identifies effective professional-patient communication as a key factor in obtaining positive results in terms of patient physical and emotional health (Shorey et al., 2018). Good communication improves patient-perceived satisfaction in healthcare processes and therefore also in the quality of their healthcare (Kourkouta \& Papathanasiou, 2014); it also helps achieve greater adherence to prescribed treatments and compliance with recommended preventive activities (Holzinger et al., 2019). In contrast, inadequate communication is linked not only with lower satisfaction levels, but also with adverse events secondary to clinical errors (Guetterman et al., 2019).

Therefore, the acquisition of communication skills should be of special relevance in the training of health care professionals (Mata et al., 2019). However, the literature shows that extraordinarily little specific content on communication skills is currently included in their curricula (FerrándezAntón et al., 2020; Ferreira-Padilla, Ferrández-Antón, Baleriola-Júlvez, \& Almeida-Cabrera, 2015). Rather, the education of healthcare professionals tends to place a strong emphasis on the acquisition of technical skills to the detriment of nontechnical skills such as communication skills (Jepsen, Østergaard, \& Dieckmann, 2014). These factors could explain the reports by nursing professionals that they do not feel sufficiently prepared in terms of communication skills (Foà et al., 2016), even though they perceive the learning of communication skills as an important and useful factor in professional practice (Coleman \& McLaughlin, 2019). 
66

67

68

69

70

71

72

73

74

75

76

77

78

79

80

81

82

83

84

85

86

87

88

89

90

91

92

93

94

95

96

97

98

99

100

101

102

103

104

105

106

107

108

109

110

111

112

\section{Background}

Communication skills can be acquired and improved through training (Cannity et al., 2020). Indeed, the European Higher Education Area (European Commission, 2005) is currently focusing its education on learning competencies which involve studying and integrating conceptual, attitudinal, and procedural dimensions into teaching (Tejada-Fernández \& Ruiz-Well, 2016). Therefore, nursing curricula should not only include communication skills with an emphasis on theoretical content and skills acquisition but should also promote positive attitudes towards using these skills (Woloschuk, Harasym, \& Temple, 2004). As suggested in the literature, attitudes are a key component in the promotion of future behaviours (Sheeran et al., 2016). However, implementing a skills-based learning approach involves incorporating and developing new evaluation methodologies and resources and requires valid tools that are objective and reliable (MacLean et al., 2017) to assess attitudes towards communication skills in educational plans (Molinuevo \& Torrubia, 2011).

Several instruments are available to assess attitudes towards communication in clinical practice. For example, the Nurses' Attitudes Towards Communication with Patients Scale (ACO in its Spanish initialism; Espert \& del Carmen, 2016) was developed to evaluate the attitudes of nursing students in terms of their behavioural, cognitive, and affective dimensions. However, the content of its items focused on hospitalisation situations applicable to certain specific nursing contexts; for example, the item "Information must be provided to the patient and/or their family about the nursing care being provided”. Another instrument, the Communication Skills Attitude Scale (CSAS; Rees et al., 2002), is widely used internationally. The items included in this twodimensional scale address situations commonly encountered by medical students, with items such as "In order to be a good doctor I must have good communication skills" or "Nobody is going to fail their medical degree for having poor communication skills".

Finally, the Attitudes Towards Medical Communication Scale (Langille et al., 2001), is a short, one-dimensional scale which has been shown to have adequate psychometric properties. This instrument has several advantages compared to the other two: it is the shortest, a total construct score can be obtained from it, and the item content addresses general aspects of clinical communication skills that could be universally applicable to different health professionals. However, it has not yet been translated into Spanish or validated for use in this language.

Therefore, the objectives of this present study were to: (a) cross-culturally adapt and validate a scale to measure attitudes towards communication in a sample of nursing students in the Spanish environment; (b) describe the perceived attitudes of fourth-year nursing degree students towards communication.

\section{Materials \& Methods}

\section{Design}

We conducted an instrumental study designed to develop an evaluation tool, which also included the generation or adaptation of new items and the examination of their psychometric properties (Carretero-Dios \& Pérez, 2007). First, we adapted the scale into the Spanish context by applying a standardised linguistic validation procedure. After that, we determined the structural equivalence between the Spanish version and the original instrument and evaluated its psychometric properties.

\section{Linguistic validation}

We used a standard linguistic validation process (Acquadro et al., 2005) to obtain the Spanish version of the scale. First, two bilingual philologist translators whose mother tongue was Spanish, 
113 who were not linked to the project or study subject, and with experience in the field of health 114 sciences translations/adaptations, translated the original English version into Spanish. Using both 115 these direct translations, and after a consensus committee meeting, a first draft of the Spanish 116 version was approved. The committee comprised two nurses with experience in adapting and 117 validating scales in the healthcare context and a linguist who specialised in cross-cultural 118 adaptation procedures.

119 Subsequently, two bilingual philologist translators whose mother tongue was English (one British 120 and one American), who had no connection to the project or the subject of study and did not 121 know the original English version of this questionnaire, independently translated the first Spanish 122 consensus translation back into English in a blinded back-translation process. The committee 123 reconvened to compare the two back-translations with the original English version and agreed 124 upon a preliminary version in Spanish. This version was subsequently used to conduct the 125 cognitive interviews.

126 The four translators were asked to assess the degree of difficulty of the direct and reverse 127 translations of the items (on a scale of 1 to 10) and to classify the changes they had made into 128 three categories (A, B, C). Type A changes were when no translation changes had been required 129 and the sentence retained the same syntactic structure. Type B changes-morphosyntactic (B1), 130 lexical-semantic (B2), or sociocultural (B3) - were changes that had been implemented to 131 maintain equivalence. Items with type $C$ changes were those where some of the items were not 132 applicable in the context of the language into which it had been translated.

133 To examine the interpretability of the questionnaire, 8 cognitive interviews were carried out with 134 nursing students; all of them were women and their mean age was 19.88 years $(S D=1.25) ; 4$ 135 (50\%) were first-year students and 4 were fourth-year students. All the participants completed the 136 final translation back-translation consensus version of the questionnaire. The interviews were 137 carried out by two trained nurses who were experts in conducting these types of interviews. 138 Participants were asked to read the questionnaire aloud and to answer it while also indicating if 139 they had understood the meaning of each item or if there were any unclear concepts. In addition, 140 these participants were asked if they had understood the response alternatives and instructions, 141 they had received prior to completing the questionnaire. Finally, they assessed the scale and they 142 considered if any important items had been omitted.

\section{Setting and sample}

145 The data was collected between June and October 2019. The inclusion criteria were: (1) 146 enrolment in a nursing course at the University of Alicante ;(2) taking any fourth-year course; 147 and (3) a fluent understanding of written and spoken Spanish. Students who had an Erasmus 148 agreement who did not have an adequate knowledge of Spanish were excluded from the study. 149 All the nursing students enrolled in a fourth-year nursing course subject at one of the 150 abovenamed universities were invited to participate.

151 Of the total eligible participants $(n=400)$, a total of 255 students completed the questionnaire; 152 thus, the response rate was 63.75\%. Of the total sample, 52 students $(20.39 \%)$ belonged to the 153 2018/19 academic year and a total of 203 students came from the 2019/20 academic year 154 (79.61\%). 
157 An ad hoc questionnaire was developed to assess the sociodemographic variables of the participants, which included age, gender, nationality (Spanish or 'other'), and marital status (single, married/cohabiting, separated/divorced, or widowed). In addition, these students were asked about any training in communication they had received during their nursing degree or in any other context.

To assess nursing students' attitudes towards communication, linguistic validation of the Attitudes Towards Medical Communication Scale was used (Langille et al., 2001). This onedimensional measurement instrument contains 12 items with a Likert-type response scale with 5 response options - from 'strongly disagree' (1) to 'strongly agree' (5). The total score ranges from 12 to 60 points, where the higher the score, the more positive the participants' attitude towards communication. In its original version, this scale had an adequate internal consistency of 1680.74.

169 To assess communication self-efficacy, we used the Spanish version (manuscript in progress) of the Self-Efficacy Questionnaire (SE-12; Axboe Christensen et al., 2016). This one-dimensional scale contains 12 items with a Likert-type response scale and 11 response options ranging from

172 'very insecure' (1) to 'very confident' (10); we also added the element 'not relevant'. This scale 173 was developed to assess the level of self-efficacy for the clinical communication skills acquired

174 during nursing training courses. The total score ranges from 12 to 120 points, where the higher 175 the score, the higher the students' confidence in the communication skills they used with patients.

176 The original version has a high internal consistency $(\dot{\alpha}=0.95)$ and an adequate test-retest score $177 \quad(I C C=0.71)$.

\section{Procedure}

Details of this work were presented along with the request for informed consent to participation in this study. Participants were invited to participate through the internal communications system of the university institution (Virtual Campus). To maximise the response rate, we followed a standardised methodology and sent three reminders, sent one week apart from each other, which encouraged participation and provided the link to the questionnaire.

\section{Data analysis}

187 R software (version 3.4.0, R Core Team, 2017, 2014) was used in the confirmatory factor analysis (CFA) and internal consistency analysis. Scale performance, including floor and ceiling effects, was also analysed. The literature considers a floor or ceiling effect to have been reached when more than $15 \%$ of the participants in the lower and upper range, respectively, responded (Lim et al., 2015). Following the criteria published by Rhemtulla et al. (2012), we considered our data to be ordinal. The robust weighted least squares means and variance (WLSMV) estimation method from the Lavaan package was used for the analysis of the ordinal data (Rhemtulla et al., 2012). 
197 Values exceeding 0.90 were considered adequate for the CFI and TLI indicators (Bentler, 1990;

$198 \mathrm{Hu} \&$ Bentler, 1999). For the RMSEA index, values less than 0.5 indicated an adequate fit 199 (Brownie, 1993; Green \& Yang, 2009).

200 The ordinal alpha coefficient, considering the estimated model, was used to analyse the internal

201 consistency of the instrument, and was considered more accurate for the categorical response 202 scales (Zumbo et al., 2007). This measure is considered an unbiased estimator of internal 203 consistency as long as the essentially tau-equivalent model fits the data (McDonald, 1999). The 204 self-efficacy in communication skills variable was used to assess the construct validity of the 205 instrument using the Pearson correlation coefficient $(r)$. We required our results to meet the 206 consensus-based standards for the selection of health measurement instruments (COSMIN; 207 Mokkink et al., 2017) recommended correlations (between 0.3 and 0.5) because these instruments 208 measured different but related constructs. Finally, a descriptive analysis (means and SDs) was 209 performed for the scale for the perceived attitude towards communication in nursing students.

\section{Ethical issues}

212 This study followed the criteria established by the Declaration of Helsinki and the European 213 Union Standards of Good Clinical Practice and obtained approval by the Bioethics Committee at 214 the University of Alicante (reference number: UA-2018-10-24). All the participants received 215 information about the voluntary nature of their participation, the possibility of withdrawal of their 216 consent at any time, and the planned treatment of the collected data. All the data obtained was 217 treated confidentially and used exclusively for research purposes.

\section{Results}

\section{Linguistic validation}

\section{Translation-back-translation process}

223

The average degree of difficulty of the translation ranged from 2 (item 5 ) to 6 (item 1) on a scale of 1 to 8 . The average difficulty of the back-translation ranged from 1.5 (items 1 and item 5) to 8.5 (item 8) on a scale of 1 to 9 . In both the translation and back-translation, most of the changes required were of the morphosyntactic (B1) or lexical-semantic (B2) type. No item required type $\mathrm{C}$ changes. Of note, the translators did not agree on the difficulty level of items 3 and 6 in the translation or in the back-translation.

\section{Cognitive interviews}

232

233

234

235

236

Participants experienced comprehension difficulties for items 3, 6, 9, and 10. Item 3 was exceedingly long and difficult to understand and so, it required morphosyntactic (B1) and lexicalsemantic (B2) modifications. The difficulty for the remaining items (which also required B1 and B2 changes) was associated with the use of specific expressions. For item 6 we solved this by changing “...the patient experience...” to “...the patients' experience of their disease”. In the case of item 9, we clarified the term “...psychosocial problems...” by adding some examples, “...psychosocial problems (for example, family or economic problems, etc.)”. For item 10, the 
238

239

240

241

242

243

244

245

246

247

248

249

250

251

252

253

254

255

256

257

258

259

260

261

262

263

264

265

266

267

268

269

270

271

272

273

274

275

276

277

278

279

280

281

expression “...health results...” was made clearer by changing it to “...health results (for example, readmissions, quality of life, etc.)”.

\section{Evaluation of psychometric properties} Sample sociodemographic data

Table 1 shows the sociodemographic data for the 255 participants, of which, 82\% were women $(n=209)$. The mean age of the cohort was 22.66 years $(S D=4.75)$, with an age range between 18 and 48 years.

\section{Scale performance and psychometric properties}

The scale performance results are shown in table 2; ceiling effects were observed for all the items included in the scale. The CFA showed that the data fit adequately to the original structure (CFI = 0.96; TLI $=0.95$; RMSEA $=0.03$ [95\% CI $=0.00-0.05]$ ) (Table 3). The estimated factor loads for most of the items varied from 0.24 to 0.72 , except for item 3 , which showed a factor load of 0.04. Elimination of item 3, "In healthcare provision teams, cohesion is desirable, but one professional alone can do little to promote it”, improved the data fit (CFI = 0.99; TLI = 0.99; RMSEA $=0.01$ [95\% CI $=0.00-0.05]$ ). The estimated factor loads of the items varied from 0.24 to 0.72 (Figure 1). Lastly, because the measures were essentially tau-equivalent (i.e., all the items had the same factor load), we tested a more restricted estimation model and found that the data continued to fit the model, although with a slightly poorer parameter results (CFI =0.93; TLI = 0.93; RMSEA $=0.04$ [95\% CI = 0.004-0.06]).

The internal consistency, calculated with the alpha ordinal, and considering the specified model after eliminating item 3, was 0.75 . Furthermore, to assess the construct validity, the total scores obtained from the attitude and self-efficacy towards communication poorly correlated but were statistically significant $(r=0.21, p=.003 ; n=203)$.

\section{Descriptive data for the participants' attitudes towards communication skills}

The overall scale score ranged between 43 and 55, with a mean of $52.62(S D=2.42)$. Statistically significant differences according to gender were found in the overall scores, where women obtained a higher mean score $(M=52.89$; $S D=2.13)$ compared to men $(M=51.35 ; S D=3.16$; Mann-Whitney $U=3.453, p=0.002)$. No significant differences were found between the 2018/2019 and 2019/2010 cohorts (Mann-Whitney $U=4.861 ; p=0.37$ ).

\section{Discussion}

The purpose of this present study was to validate the Spanish translation of the Attitudes Towards Medical Communication Scale (Langille et al., 2001) in a sample of nursing students in the Spanish setting and to describe the attitudes perceived by nursing-degree students. Our findings indicated that the Spanish version of the scale, Attitude Towards Health Communication (AHCS), called the 'Actitudes de la Comunicación Sanitaria' scale in Spanish (see Supplemental Files) is a valid and reliable instrument to assess the attitudes of nursing-degree students towards communication. In addition, this scale has also been validated in a health context different from the one in which it was originally developed (for use in medical students). Therefore, we concluded that this is a valid scale for the extensive analysis of attitudes towards communication in other professional healthcare contexts. 
282 The CFA showed that the scale maintained its original structure and had adequate adjustment 283 indices when used to assess Spanish nursing students. However, given the difficulty in 284 understanding item 3 in the cognitive interviews we performed, as well as the low factor loading 285 of this item in the CFA, we omitted item 3 and modified the final Spanish version of the scale to 286 contain only 11 items. Future research will be needed to check the adjustment of the data in other 287 contexts to confirm the original structure and the operation of item 3.Following recommendations 288 based on current evidence (Black et al., 2014; Yang \& Green, 2011), the internal consistency was 289 initially adjusted based on the specifications in the structural equation modelling. The internal 290 consistency was adequate (> 0.70; George \& Mallery, 2003) and was similar to that obtained in 291 the original version of the scale (Langille et al., 2001).

292 In terms of construct validity, we found a weak positive correlation (Cohen, 1992) between the 293 attitudes towards communication score and the SE-12 scale (Axboe et al., 2016), although this 294 factor was not evaluated in the original version (Langille et al., 2001). The literature indicates 295 that there is a relationship between these two variables in the educational field and that they are 296 both relevant in professional practice (Sung, Huang, \& Lin, 2015) and future behaviour (Sheeran 297 et al., 2016). However, a recent study by our team (Juliá-Sanchís et al., 2020) observed only 298 moderate correlations $(r=0.35)$ between perceived abilities in communication skills and scores 299 on the Attitudes Towards Communication Scale, including on the 12 items in the original version. 300 Thus, we recommend continuing the analysis of the construct validity of this scale in future lines 301 of research.

302 Our results showed that the items on this scale had a ceiling effect (Lim et al., 2015), which 303 suggests that it might not evaluate a wide range of the potential variability among students who 304 have positive attitudes towards communication, at least for samples with similar characteristics to 305 the cohort considered in this study. However, it should be noted that the previous communication 306 training of these students was mostly received as part of their formal compulsory training. Thus, the fact that previous studies highlight specific training as an influencing factor in attitudinal improvement (Lichtenstein et al. 2018) could explain their high scores in attitudes towards communication.

310 In terms of a general description of the attitudes of nursing students towards communication, our 311 results showed that high scores were as high as those shown in other national studies in students 312 of other health professions (Molinuevo et al., 2016), and specifically among those in nursing 313 contexts (Molinuevo \& Torralba, 2011). Similar results were also found in international studies in 314 medical students (Langille et al., 2001) and among nursing professionals (Cronin \& Finn, 2017; 315 Panczyk et al., 2019). Therefore, it seems that students have positive attitudes towards 316 communication, regardless of the type of healthcare profession they work in and the environment 317 in which they live. Nonetheless, much less work has been done in nursing students compared to 318 similar studies in medical or dental students (Abdrbo, 2017). Hence, this current study helps to 319 increase and update our knowledge about this issue in nursing students. Furthermore, these 320 results have important implications within the European Higher Education Area given the 321 emphasis this body places on the acquisition and evaluation of attitudinal competences in the 322 learning-teaching process (European Commission, 2005). 
323 Regarding the sociodemographic factors of this cohort, as reported elsewhere in the literature 324 (Molinuevo \& Torrubia, 2011; Koponen et al., 2012), we also detected gender-related differences 325 in our cohort. Previous studies have revealed that male students had greater difficulty in learning 326 communication skills and that this may be because the acquisition of these skills requires 327 emotional exposure, which can be more characteristic of women (Loffler-Stastka et al., 2016). 328 Thus, according to this previous work, nursing schools face a major challenge when trying to 329 improve attitudes towards better acquisition of communication skills among male students (Gude 330 et al., 2020). However, more studies with a gender perspective (Lichtenstein et al. 2018) will be 331 needed to fully assess whether there are indeed currently gender-based differences in nursing, and 332 to analyse what factors influence attitudes towards communication so that these can be 333 considered when providing student training.

334

335

\section{Limitations}

336 Firstly, we used the natural opportunity presented by the enrolment of nursing students into their courses to obtain a convenience sample. Although participation was always voluntary and did not influence their evaluation outcomes, this may have compromised the external validity of our results. Therefore, the structure of this scale should be confirmed with representative and randomised nursing student samples at the national level to guarantee the that these results can be generalised. Furthermore, the validity of the Spanish version of this scale only applies to

342 undergraduate nursing students. Therefore, if it is to be used in other sample cohorts such as 343 postgraduate students or clinical healthcare professionals, including nursing professionals, evidence for the validity of this scale must first be obtained for these groups.

345 Finally, the overall participation rate in this work was moderate, and specifically, was low in the 346 2018/2019 cohort and so future research should aim to increase these participation levels. One reason for this may have been the timing of our data collection, which was preferable in the 2019/2020 cohort because these students were starting the academic year. Therefore, the timing of the data collection for the $2019 / 2020$ period corresponded to the time in which the theoretical part of the course was taught, and when the students were more strongly linked to the university. In contrast, in the 2018/2019 cohort, the students were surveyed at the end of the academic year when they were already engaged in their clinical practices in hospitals and had a weaker association with the university. Nevertheless, this characteristic had no impact on the internal validity of the study because no differences were found in the attitude towards communication scores variable that we were specifically focusing on in this current validation study.

\section{Conclusions}

360

The AHC-S is valid and reliable tool for assessing the attitudes of nursing degree students; it

361 represents a useful tool for university professors in the assessment of health professions given that it is self-administered, quick and easy to complete, and helps provide useful data for deciding whether improvements or changes in training programs are required when low levels of certain attitudes are identified. Future lines of research should be aware of the ceiling effect of the scale and should aim to validate this tool with students and health professionals in other contexts. 


\section{References}

367 Abdrbo, A. (2017). Assesment of nursing students' communication skills. Nursing Education Perspectives, 38(3), 149-151. Doi: 10.1097/01.nep.0000000000000126

370

371

372

373

374

375

376 patient-reported outcomes (PRO) instruments. Quality of life research 14, 1791-1792. doi:10.1007/s11136-005-5367-1.

Axboe, M.K., Christensen, K.S., Kofoed, P., Ammentorp, J. (2016). Development and validation of a self-efficacy questionnaire (SE-12) measuring the clinical communication skills of health care professionals. BMC Medical Education 16, 272. doi:10.1186/s12909-016-07987

Bentler, P.M. (1990). Comparative fit indexes in structural models. Psychological Bulletin Journal 107(2), 238-246. doi:10.1037/0033-2909.107.2.238

Black, R.A., Yang, Y., Beitra, D., McCaffrey, S. (2014). Comparing Fit and Reliability Estimates of a Psychological Instrument using Second-Order CFA, Bifactor, and Essentially TauEquivalent (Coefficient Alpha) Models via AMOS 22. Journal Psychoeducation Assessesment 33(5), 451-472. doi:10.1177/0734282914553551

Cannity, K. M., Banerjee, S. C., Hichenberg, S., Leon-Nastasi, A. D., Howell, F., Coyle, N., ... Parker, P. A. (2020). Acceptability and Efficacy of a Communication Skills Training for Nursing Students: Building Empathy and Discussing Complex Situations. Nurse Education in Practice, 102928. doi:10.1016/j.nepr.2020.102928

Carretero-Dios, H., Pérez, C. (2007). Standards for the development and review of instrumental studies: considerations about test selection in psychological research. International Journal of Clinical and Health Psychology 7(3), 863-882. Retrieved from http://digibug.ugr.es/handle/10481/32752

Cohen, J. (1992). A power primer. Psychological Bulletin, 112(1), 155-159. doi: 10.1037/00332909.112.1.155

Coleman, D., McLaughlin, D. (2019). Using simulated patients as a learning strategy to support undergraduate nurses to develop patient-teaching skills. British Journal of Nursing 28(20), 1300-1306. doi:10.12968/bjon.2019.28.20.1300

Cronin, J. A., Finn, S. (2017). Implementing and Evaluating the COMFORT Communication in Palliative Care Curriculum for Oncology Nurses. Journal of Hospice \& Palliative Nursing, 19(2), 140-146. doi:10.1097/njh.0000000000000320

European Commission. (2005). Directive 2005/36/EC of the European Parliament and of the Council on the recognition of professional qualifications. Official Journal European Union 48, 22-142.

Espert, G., del Carmen, M. (2016). Actitudes hacia la comunicación, inteligencia emocional y empatía en enfermería [Attitudes towards communication, emotional intelligence and empathy in nursing]. Retrieved from: http://roderic.uv.es/handle/10550/54130

Ferrández-Antón, T., Ferreira-Padilla, G., del-Pino-Casado, R., Ferrández-Antón, P., BaleriolaJúlvez, J., Martínez-Riera, J.R. (2020). Communication skills training in undergraduate 
406

407

408

409

410

411

412

413

414

415

416

417

418

419

420

421

422

423

424

425

426

427

428

429

430

431

432

433

434

435

436

437

438

439

440

441

442

443

444

445

446

nursing programs in Spain. Nurse Education in Practice 42, 102653. doi:10.1016/j.nepr.2019.102653

Ferreira-Padilla, G., Ferrández-Antón, T., Baleriola-Júlvez, J., Almeida-Cabrera, R. (2015). Competencia en comunicación en el currículo del estudiante de Medicina de España (19902014): de la Atención Primaria al Plan Bolonia. Un estudio descriptivo. [Communication skills in the curriculum of Medical students from Spain (1990-2014): From the Primary Health Care to the Bologna Plan. A descriptive study] Atención Primaria, 47(7), 399-410. doi:10.1016/j.aprim.2014.09.007

Foà, C., Cavalli, L., Maltoni, A., Tosello, N., Sangilles, C., Maron, I., Borghini, M., Artioli, G. (2016). Communications and relationships between patient and nurse in Intensive Care Unit: knowledge, knowledge of the work, knowledge of the emotional state. Acta BioMedica: Atenei Parmensis, 87(4-S), 71-82.

George, D., Mallery, P. (2003). SPSS for Windows step by step: A simple guide and reference. 11.0 update (4th ed). Boston: Allyn \& Bacon.

Green, S.B., Yang, Y. (2009). Reliability of Summed Item Scores Using Structural Equation Modeling: An Alternative to Coefficient Alpha. Psychometrika 74(1), 155-167. doi:10.1007/s11336-008-9099-3

Gude, T., Tyssen, R., Anvik, T., Grimstad, H., Holen, A., Holen, A., Baerheim, A., Vaglum, P., \& Løvseth, L. (2020) (2020). Have medical students' attitudes towards clinical communication skills changed over a 12- year period? A comparative long-term study. BMC medical education, 20(1), 11. https://doi.org/10.1186/s12909-019-1915-1

Guetterman, T.C., Sakakibara, R., Baireddy, S., Kron, F.W., Scerbo, M.W., Cleary, J.F., Fetters, M.D. (2019). Medical students' experiences and outcomes using a virtual human simulation to improve communication skills: Mixed methods study. Journal of Medical Internet Research 21(11), e15459. doi:10.2196/15459

Holzinger, A., Langs, G., Denk, H., Zatloukal, K., Mueller, H. (2019). Causability and explainability of AI in medicine. Data Mining and Knowledge Discovery 9(4), e1312. doi:10.1002/widm.1312

Hu, L., Bentler, P.M. (1999). Cutoff criteria for fit indexes in covariance structure analysis: Conventional criteria versus new alternatives. Structural Equation Modeling 6(1), 1-55. doi:10.1080/10705519909540118

Jepsen, R. M. H. G., Østergaard, D., Dieckmann, P. (2014). Development of instruments for assessment of individuals' and teams' non-technical skills in healthcare: a critical review. Cognition, Technology \& Work, 17(1), 63-77. doi:10.1007/s10111-014-0306-y

Juliá-Sanchis, R., Cabañero-Martínez, M. J., Leal-Costa, C., Fernández-Alcántara, M., Escribano, S. (2020). Psychometric Properties of the Health Professionals Communication Skills Scale in University Students of Health Sciences. International Journal of Environmental Research and Public Health, 17(20), 7565. doi: 10.3390/ijerph17207565

Koponen, J., Pyörälä, E., Isotalus, P. (2012). Comparing three experiential learning methods and their effect on medical students'attitudes to learning communication skills. Medical Teacher 34(3) 198-207. doi:10.3109/0142159X.2012.642828. 
447

448

449

450

451

452

453

454

455

456

457

458

459

460

461

462

463

464

465

466

467

468

469

470

471

472

473

474

475

476

477

478

479

480

481

482

483

484

485

486

487

488
Kourkouta, L. Papathanasiou, I.V. (2014). Communication in nursing practice. Materia SocioMedica 26(1) 65-67. doi:10.5455/msm.2014.26.65-67

Langille, D.B., Kaufman, D.M., Laidlaw, T.A., Sargeant, J., MacLeod, H. (2001). Faculty attitudes towards medical communication and their perceptions of students' communication skills training at Dalhousie university. Medical Education 35(6), 548-554. doi:10.1046/j.1365-2923.2001.00921.x

Lichtenstein, N.V., Haak, R., Ensmann, I., Hallal, H., Huttenlau, J., Krämer, K., Krause, F., Matthes, J., Stosch, C. (2018). Does teaching social and communicative competences influence dental students' attitudes towards learning communication skills? A comparison between two dental schools in Germany. GMS Journal for Medical Education 35(2). doi:10.3205/zma001165

Lim, C.R., Harris, K., Dawson, J., Beard, D.J., Fitzpatrick, R., Price, A.J. (2015). Floor and ceiling effects in the OHS: an analysis of the NHS PROMs data set. BMJ Open 5(7), e007765. doi:10.1136/bmjopen-2015-007765

Loffler-Stastka, H., Seitz, T., Billeth, S., Pastner, B., Preusche, I., Seidman, C. (2016). Significance of gender in the attitude towards doctor-patient communication in medical students and physicians. Wien Klin Wochenschr 128(17-18), 663-8. doi:10.1007/s00508016-1054-1

MacLean, S., Kelly, M., Geddes, F.,Della, P. (2017). Use of simulated patients to develop communication skills in nursing education: An integrative review. Nurse Education Today 48, 90-98. doi:10.1016/j.nedt-2016.09.018

Mata, Á., Azevedo, K., Braga, L. P., Medeiros, G., Oliveira Segundo, V. H., Bezerra, I., Pimenta, I., Nicolás, I. M., Piuvezam, G. (2019). Training programs in communication skills to improve self-efficacy for health personnel: Protocol for a systematic review and metaanalysis. Medicine, 98(33). doi:10.1097/MD.0000000000016697

McDonald, R.P. (1999). Test theory: A unified treatment. Mahwah, NJ: Lawrence Erlbaum Associates.

Molinuevo, B., Aradilla-Herrero, A., Nolla, M., Clèries X. (2016). A comparison of medical students', residents' and tutors' attitudes towards communication skills learning. Education and Health 29(2), 132-135. doi:10.4103/1357-6283.188755

Molinuevo, B., Torrubia, R. (2011). Validation of the Catalan version of the communication skills attitude scale (CSAS) in a cohort of south European medical and nursing students. Education and Health 24, 499

Mokkink, L. B., Prinsen, C. A., Patrick, D. L., Alonso, J., Bouter, L. M., De Vet, H. C., Terwee, C. B. (2017). COSMIN methodology for systematic reviews of Patient-Reported Outcome Measures (PROMs); user manual. Retrieved from http://www.cosmin.nl.

Panczyk, M., Iwanow, L., Zarzeka, A., Jaworski, M., Gotlib, J. (2019). Communication skills attitude scale: a translation and validation study in a sample of registered nurses in Poland. BMJ Open 9(5), e028691. doi:10.1136/bmjopen-2018-028691

Rees, C., Sheard, C., Davies, S. (2002). The development of a scale to measure medical students' attitudes towards communication skills learning: The communication skills attitude scale (CSAS). Medical Education 36(2),141-147. doi:10.1046/j.1365-2923.2002.01072.x 
489

490

491

492

493

494

495

496

497

498

499

500

501

502

503

504

505

506

507

508

509

510

511

512

513
Rhemtulla, M., Brosseau-Liard, P.É., Savalei, V. (2012). When can categorical variables be treated as continuous? A comparison of robust continuous and categorical SEM estimation methods under suboptimal conditions. Psychology Methods 17(3), 354-373. doi:10.1037/a0029315

Sheeran, P., Maki, A., Montanaro, E., Avishai-Yitshak, A., Bryan, A., Klein, W. M. P., Miles, E., Rothman, A. J. (2016). The impact of changing attitudes, norms, and self-efficacy on health-related intentions and behavior: A meta-analysis. Health Psychology, 35(11), 11781188. doi:10.1037/hea0000387

Shorey, S., Kowitlawakul, Y., Devi, M.K., Chen, H., Soong, S.K.A., Ang, E. (2018). Blended learning pedagogy designed for communication module among undergraduate nursing students: A quasi-experimental study. Nurse Education Today 61, 120-126. doi:10.1016/j.nedt.2017.11.011.

Sung, S.-C., Huang, H.-C., Lin, M.-H. (2015). Relationship Between the Knowledge, Attitude, and Self-Efficacy on Sexual Health Care for Nursing Students. Journal of Professional Nursing, 31(3), 254-261. doi:10.1016/j.profnurs.2014.11.001

Tejada-Fernández, J., Ruiz-Bueno, C. (2016). Evaluation of professional competences in Higher Education: Challenges and implications. Education XX1 19(1), 17-38, doi:10.5944/educXX1.12175

Yang, Y., Green, S.B. (2011). Coefficient alpha: A reliability coefficient for the $21^{\text {st }}$ Century? Journal of Psychoeducational Assessment 29(4), 377- 392. doi:10.1177/0734282911406668

Woloschuk, W., Harasym, P. H., Temple, W. (2004). Attitude change during medical school: A cohort study. Medical Education, 38(5), 522-534.

Zumbo, B.D., Gadermann, A.M., Zeisser, C. (2007). Ordinal versions of coefficients alpha and theta for Likert rating scales. Journal of Modern Applied Statistical Methods,6, 21-29. 
Figure 1

Figure 1. Confirmatory factor analysis

Confirmatory factor analysis without item 3 graph extracted via the Lavaan package in the $\mathrm{R}$ freeware; $\mathrm{AHC}=$ Attitudes towards Health Communication, Spanish version of Attitudes towards Medical Communication Scale (Langille et al., 2001).

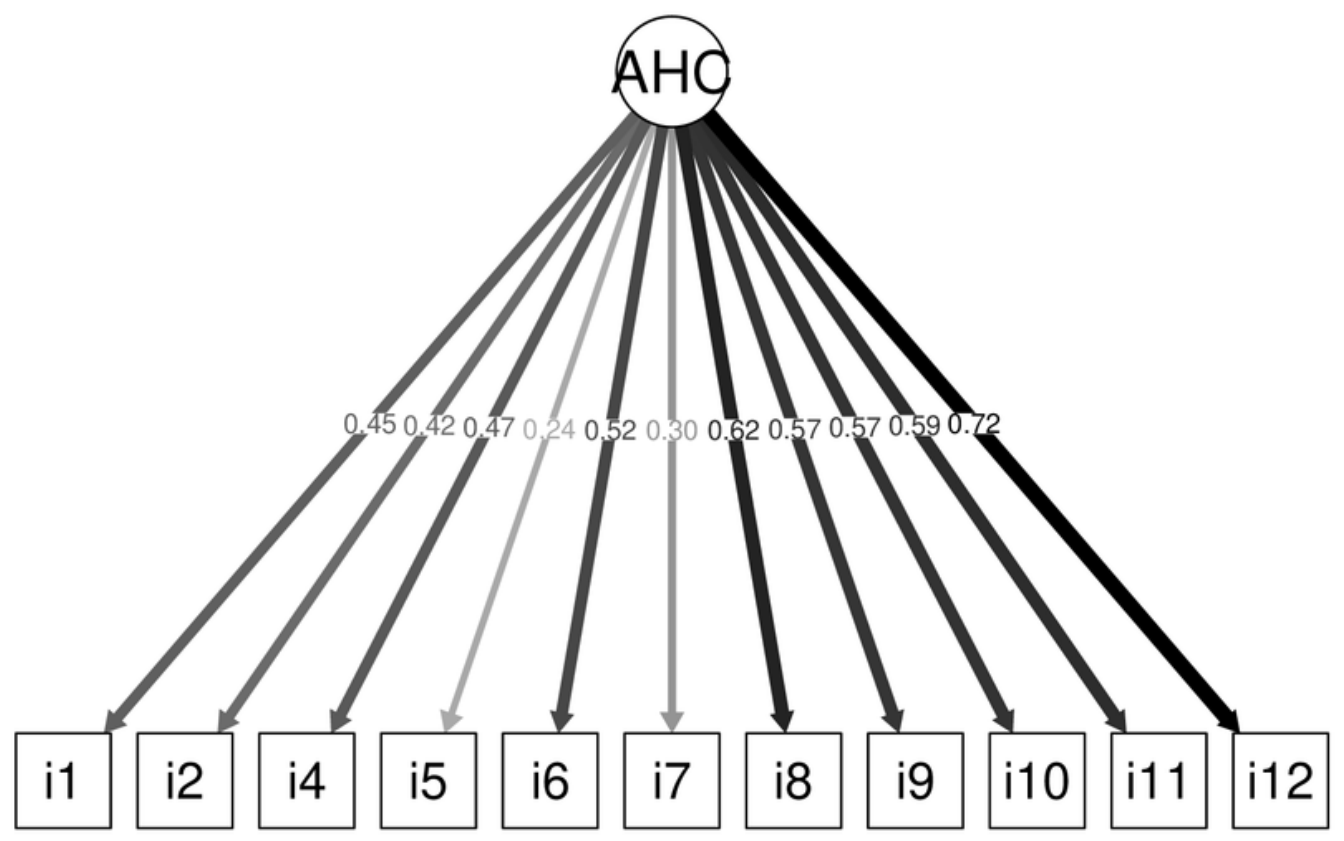




\section{Table $\mathbf{1}$ (on next page)}

Table 1. Socio-demographic characteristics of participants $(N=255)$

$M=$ Mean; SD = Standard deviation; ${ }^{\mathrm{a}}$ This analysis was performed with 203 participants. 
1 Table 1. Socio-demographic characteristics of participants $(\mathrm{N}=255)$

2

3

4

5

6

7

8

9

10

11

12

13

14

15

16

17

18

19

20

21

22

23 Note: $\mathrm{M}=$ Mean; $\mathrm{SD}=$ Standard deviation; ${ }^{\text {a }}$ This analysis was performed with 203 participants. 


\section{Table 2 (on next page)}

Table 2. Performance of the scale

Note: $\mathrm{M}=$ Mean; $\mathrm{SD}=$ Standard deviation; Min = Minimum; Max = Maximum. 
1 Table 2. Performance of the scale

\begin{tabular}{|c|c|c|c|c|c|c|c|}
\hline Item & Min & Max & M (SD) & Skewness & Kurtosis & $\begin{array}{l}\text { Floor effect } \\
\text { n (\%) }\end{array}$ & $\begin{array}{l}\text { Ceiling effect } \\
\text { n (\%) }\end{array}$ \\
\hline Item 1 & 3 & 5 & $4.87(0.37)$ & -2.83 & 7.78 & $0(0)$ & $224(87.80)$ \\
\hline Item 2 & 1 & 5 & $4.75(0.84)$ & -3.80 & 13.87 & $10(3.90)$ & $225(88.20)$ \\
\hline Item 3 & 1 & 5 & $3.28(1.26)$ & -.30 & -.95 & $28(11)$ & $48(18.80)$ \\
\hline Item 4 & 1 & 5 & $4.75(0.51)$ & -3.55 & 16.91 & $1(0.4)$ & $215(84.30)$ \\
\hline Item 5 & 3 & 5 & $4.95(0.25)$ & -4.71 & 23.75 & $0(0)$ & $242(94.90)$ \\
\hline Item 6 & 1 & 5 & $4.75(0.60)$ & -3.59 & 17.11 & $3(1.2)$ & $205(80.4)$ \\
\hline Item 7 & 1 & 5 & $4.65(0.57)$ & -1.93 & 6.01 & $1(0.4)$ & $176(69)$ \\
\hline Item 8 & 3 & 5 & $4.76(0.46)$ & -1.58 & 1.39 & $0(0)$ & $196(76.9)$ \\
\hline Item 9 & 3 & 5 & $4.69(0.58)$ & -1.69 & 1.81 & $0(0)$ & $190(74.5)$ \\
\hline Item 10 & 3 & 5 & $4.83(0.40)$ & -2.11 & 3.53 & $0(0)$ & $213(83.5)$ \\
\hline Item 11 & 1 & 5 & $4.77(0.64)$ & -3.98 & 18.84 & $4(1.6)$ & $212(83.1)$ \\
\hline Item 12 & 1 & 5 & $4.80(0.50)$ & -3.51 & 17.08 & $1(0.4)$ & $213(83.5)$ \\
\hline
\end{tabular}

2

3

4 Note: $\mathrm{M}=$ Mean; $\mathrm{SD}=$ Standard deviation; Min = Minimum; $\mathrm{Max}=$ Maximum. 


\section{Table 3 (on next page)}

Table 3. Confirmatory analysis and internal reliability consistency $(\mathrm{N}=255)$

Note: ${ }^{a}$ Original proposed by Langille et al. (2001); ${ }^{\text {b }}$ Modified = without "ítem 3"; CFI= Comparative fix index; TLI = Tucker-Lewis index; RMSEA = Root mean square error of approximation; $\mathrm{Cl}=$ Confident interval; ${ }^{\mathrm{c}}$ Ordinal Alpha calculated across Structural Equation Model (SEM). 
1 Table 3. Confirmatory analysis and internal reliability consistency $(\mathrm{N}=255)$

2

3

4

5

6

7

8 Langille et al. (2001); ${ }^{\mathrm{b}}$ Modified = without "ítem 3"; CFI= Comparative fix index; TLI =

9 Tucker-Lewis index; RMSEA = Root mean square error of approximation; $\mathrm{CI}=\mathrm{Confident}$

10 interval; ${ }^{\mathrm{c}}$ Ordinal Alpha calculated across Structural Equation Model (SEM). 